\title{
The Power of Images, Reconsidered
}

\section{Erin L. Thompson'}

\begin{abstract}
This essay reappraises David Freedberg's foundational The Power of Images: Studies in the History and Theory of Response (University of Chicago Press, 1989), in light both of his more recent publications on iconoclasm, censorship, and the role of irrational and emotional responses to images in general and of the current global wave of iconoclastic actions.
\end{abstract}

Keywords: Neuroaesthetics. Emotion. Censorship. Universality. 
On a summer evening, protestors gathered outdoors to listen to speakers denounce the cruelties of the political authorities. Similar protests had erupted across the country, as long-simmering tensions finally boiled over. This protest, as would many others in the days to follow, ended with the participants tearing down statues they believed embodied the ideologies of the oppressive regime.

In the summer of 2020, widespread protests led to the toppling or removal into protective storage of hundreds of controversial public monuments. ${ }^{1}$ But the above description is of the evening of August 22, 1566, in the $\mathrm{Ne}$ therlandish town of 's-Hertogenbosch. ${ }^{2}$ After hearing an open-air sermon by an itinerant Protestant preacher, the large crowd rushed from church to church, singing psalms and smashing images. Two days later, the reformers held their first sermon in the town's cathedral, now purified of the paintings and statues they believed tempted viewers into idolatry or lust. These iconoclasts were part of what is known as the Beeldenstorm, the "storm of images" that swept the Netherlands in late 1566, during which almost every town in the country experienced at least one incident of image-breaking. ${ }^{3}$ While the Netherlands were at the epicenter, similar iconoclastic actions occurred all over Europe in the period, from the British Isles to the Balkans.

Although Protestants were then a small minority in the Netherlands, many Dutch Catholics also joined in the Beeldenstorm. Some were persuaded by reformers' theological arguments, believing that their contemplation of the divine would be purer without the distraction of images. Others, especially the minor nobility, chafed against Spanish rule of the Netherlands. Their eagerness to smash Catholic images was a symbol of their rebellion against Spain's Most Catholic Majesties. Many others were simply hungry. Grain shortages after the failed harvest of 1565 created receptive audiences for reform pamphlets and travelling preachers who insisted that the Church unjustly wasted its wealth on artwork.

David Freedberg's Iconoclasm (University of Chicago Press, 2021), a collection of ten new and previously published essays, helps explain why arguments

1 Thompson, Erin L. Smashing Statues: The Rise and Fall of American Monuments. New York: Norton, 2022.

2 Freedberg, David. Iconoclasm. Chicago: University of Chicago Press, 2021, pp. 67-69.

3 Freedberg, Iconoclasm, 53-94. 
about what society should look like played out in attacks on images in both 1566 and 2020. Freedberg is a professor of art history at Columbia University (and, long ago, my dissertation advisor). His publications, especially 1989's foundational The Power of Images: Studies in the History and Theory of Response (University of Chicago Press), made iconoclasm into an accepted subject for art history - something to be studied rather than hushed up. Freedberg describes himself as "haunted" by the question of what exactly it is about art that arouses such fierce responses. ${ }^{4} \mathrm{He}$ is convinced the answers lie in the "psychologically more fundamental levels of motivation."

Freedberg investigates our emotional responses to images of all sorts, from fine art to snapshots. Believing that academic art history is preoccupied with the social and historical contexts of art-making, Freedberg instead delves into "the hard, brute, and sweet reality of the image" by examining the responses we are generally embarrassed to admit even to ourselves. ${ }^{6}$

Take, for example, Alonso Cano's c. 1645-1652 painting of The Vision of Saint Bernard in the Prado, one of many similar illustrations of a popular legend about a statue of the Virgin Mary come to life. ${ }^{7}$ She squirts a jet of breastmilk directly into the praying saint's mouth to reward him for his devotion. Freedberg explains that the story is a miraculous amplification of the way images are used in many religions, not just Catholicism. This type of image "brings the transcendent to Earth," helping worshippers understand invisible mysteries by picturing them in visible forms.

Of course, Saint Bernard's encounter was regarded as exceptional. There would be nothing miraculous about the story if listeners believed a statue could lactate as easily as a living woman. Still, Freedberg is convinced that our brains initially respond to every figural image we see as if it were alive. Only afterwards do we shape this response by reassuring ourselves that the image is inanimate. If you have ever become aroused looking at an arrangement of pigments or pixels in place of an actual body, you, too, have felt

\footnotetext{
4 Freedberg, Iconoclasm, xi.

5 Freedberg, Iconoclasm, 147.

6 Freedberg, David. The Power of Images: Studies in the History and Theory of Response. Chicago: University of Chicago Press, 1989.

7 Freedberg, The Power of Images, 286-316.
} 
this power of images. Freedberg believes such responses are shared by all humans, due to "our psychological, biological, and neurological status as members of the same species." Factors like our gender, race, culture, and personal history then play a "conditioning role," modifying and shaping our ultimate reactions as well as our conscious understanding of these reactions.

Freedberg has long championed neuroaesthetics, a field of study which seeks to analyze the biological components of our response to art. Some neurological studies do seem to support Freedberg's contention that we respond images as if they were alive. For example, the same regions of our brains are activated when we see an object and when we see an image representing this object. But the promise of neuroaesthetics as yet remains largely unfulfilled. Few scientists have been willing to dedicate expensive brain-imaging studies to our responses to art, and the data we have collected remains hard to interpret. Some of this data seems to contradict Freedberg's central thesis that our initial responses to images are purely biological and pre-cognitive. For example, subjects in a 2011 study showed markedly different neurological activation in response to images they were told were painted by Rembrandt versus those they were told were copies of his works. ${ }^{8}$ This occured regardless of whether the paintings were genuine or not (the investigators randomized the descriptions), suggesting that our conscious beliefs about an image can shape our biological response.

Regardless of whether we accept his central premise about the universality of response, Freedberg's insistence on the importance of irrational, bodily, emotional responses to art is still valuable. $\mathrm{He}$ is particularly fascinated with our sexual response to images that are purportedly not intended to lead to such responses. ${ }^{9}$ Cano's painting of Saint Bernard, for instance, with its bared breast and bodily fluid passed from one partner to another, is supposed to inspire viewers to emulate the saint's chastity. Freedberg argues that this pairing of arousing response and theological goal is no accident. For him, our sexual response is precisely what allows us to conceive of images as a pathway to the divine. We respond to images of a beautiful Virgin or a handsome saint because we are attracted to their bodies. Religion's required

8 Huang, Mengfei, Holly Bridge, Martin J. Kemp, and Andrew J. Parker. Human Cortical Activity Evoked by the Assignment of Authenticity when Viewing Works of Art, in: Frontiers in Human Neuroscience, vol. 5, 134 (2011). https://www.ncbi.nlm.nih.gov/pmc/articles/PMC3225016/

9 Freedberg, The Power of Images, 317-344. 
subterfuge is to convince us that the stirring we feel is due to the subjects' spiritual qualities rather than their physical ones.

For Freedberg, sexualized looking is universal, while the manifold ways we shape or repress our arousal are the products of our particular culture and circumstances. One of The Power of Images' essential contributions to art history was its argument against the then-standard labelling of some cultures as "primitive" based on certain responses to art. Arguing that scholars overlooked the same "primitive" behavior in the modern West, Freedberg sought to collapse the supposed distinction between responding to images as aesthetically beautiful and as religiously or "magically" potent. To support this, The Power of Images discussed historical European uses of images, including hanging life-sized wax votive portraits in churches and painting traitors on prison walls so that their punishment would continue even after they were executed. ${ }^{10}$ People in all cultures and all times "vacillate between love of images and hostility toward them." All humans have been aroused by art, have kissed it and cried before it - and have broken it in deliberate attacks.

In his 1880 travelogue A Tramp Abroad, Mark Twain calls Titian's The Venus of Urbino "the foulest, the vilest, the obscenest picture the world possesses," and jokes that it was made for a brothel "and it was probably refused because it was a trifle too strong. In truth, it is a trifle too strong for any place but a public art gallery." ${ }^{11}$ Freedberg lays out what Twain recognized in his joke: the museum is a place for repression, where we can tame to power of images. In the museum, with its strict social code regulating visitors' behavior, we rationalize our responses to artworks. We (generally) do not allow ourselves to fall to our knees in prayer, act sexually, or attack the art, even if we have powerful initial responses.

The repression even extends to what we allow ourselves to think about the history of images. Although museums now rarely describe non-Western art as "primitive," it is still not common to see European artworks' original erotic, medical, or miracle-working uses described in galleries or art history lectures. We are still reluctant to admit that we respond to artworks on anything other than a purely intellectual level, despite Freedberg's plea not to forget

10 Freedberg, The Power of Images, 136-160; 246-282.

11 Twain, Mark. A Tramp Abroad. Hartford, Conn: American Publishing Co, 1880. https://www. gutenberg.org/ebooks/119 
"the elements of sexuality that live beneath sophisticated indifference" of a modern museum visitor. Titian's Venus, painted in 1534, was probably intended to rouse a young bride at a time when female orgasm was though necessary for conception. But audiences now usually ignore or reinterpret evidence of this prior use, claiming, for example, that the painting's subject is modestly covering her genitals with one hand. Algernon Swinburne, always keenly attentive to any sexual imagery, knew that this was far from the truth; as he put it in an 1864 letter, she has "four lazy fingers buried dans les fleurs de son jardin." 12 The poet marveled at the ability of viewers to remain "decently virtuous within thirty square miles" of the canvas.

While museum-going shapes the viewer's reaction, censorship and iconoclasm shape the work itself. They attempt to lessen a socially undesirable or personally intolerable response by damaging or destroying an image. A censor covers the genitals of a nude statue, while an iconoclast smashes them off. The Power of Images includes a series of case studies of attackers slashing, breaking, or throwing acid on artworks, including Rembrandt's Night Watch and one of Michelangelo's Pietas. ${ }^{13} \mathrm{~A}$ number of these attackers suffered from schizophrenia, a condition that can make it even more difficult to distinguish between living and inanimate objects. While iconoclasts who operate in groups, as during the Beeldenstorm, usually claim to have more rational theological or political aims, Freedberg argues that everyone who attacks an image does so because they find it too hard to draw the line between image and reality. For protestors, "the broadly political act becomes allied with the idiosyncratic, neurotic one."

Of course, images themselves do not determine our reactions. Individual viewers assign meaning to their initial responses to an image. For Freedberg, an image is no more capable of oppressing its viewers than a love charm has the power to seduce. If images have real-world effects, it is because of the systems of meanings into which their viewers place them. For Freedberg, iconoclasm and censorship are always "unthinking" reactions to images, repressive coverings for an irrational fear that an image might truly come alive. If you want to change the meaning of an image or how it makes people

12 Quoted in Freedberg, The Power of Images, 345.

13 Freedberg, The Power of Images, 345-428. 
feel or act, Freedberg suggests that you encourage people to reflect upon their relationship to this image. If viewers change their reactions, images can survive unharmed.

Freedberg, who describes himself as a member of the "bien-pensant liberal bourgeoisie," decries racism and the histories of oppression honored by many of the monuments that protestors have rallied against in recent years. ${ }^{14}$ Still, he cannot bring himself to condone their destruction. His own history goes some way toward explaining why. He is an expert on Netherlandish art, and his interest in iconoclasm arose from his struggle to understand the Beeldenstorm, which destroyed so many of its masterpieces. His theory of iconoclasm shies away from conclusions that might, even retroactively, justify this destruction.

Freedberg opened a graduate seminar I attended by asking, "Who were the three best landscape painters of the Dutch $17^{\text {th }}$ century?" One of my classmates suggested Jan van Goyen. "No," Freedberg said with a curt wave of his hand. "He's number four." While magisterial in his knowledge of $\mathrm{Ne}$ therlandish art and history, Iconoclasm reveals that Freedberg has not paid as close attention to contemporary destruction. The book's most concentrated essay on recent iconoclasms does not contain a single quote from a protestor seeking the removal of a monument. Freedberg does reproduce a piece of a New York Times interview with Randall L. Woodfin, the mayor of Birmingham, Alabama, in which he said that "any Confederate museum that wants this thing can have it" about his city's controversial monument. ${ }^{15}$ Woodfin was the first American official to order the removal of a Confederate monument during the 2020 protests, and Freedberg takes this statement as a cavalier rejection of the power of the monument, which has "become just a thing to be dismissed, granted free to the first willing taker." ${ }^{16}$ Freedberg concludes that Woodfin must think of the monument as "reduced to the level of raw materiality, devoid of shape or meaning." ${ }^{17}$

14 Freedberg, Iconoclasm, xix.

15 Blinder, Alan and Audra D. S. Burch. Fate of Confederate Monuments Is Stalled by Competing Legal Battles, in: New York Times, January 20, 2019. https://www.nytimes.com/2019/01/20/us/ confederate-monuments-legal-battles.html

16 Freedberg, Iconoclasm, 214.

17 Id. 
But the statement Freedberg quotes was from a 2019 interview, well before Woodfin's late-May 2020 decision to remove the monument. In fact, Woodfin, a Black lawyer in his thirties, has a nuanced understanding of the power of Confederate monuments erected long after the Civil War by politicians intent on intimidating Black citizens and preventing them from exercising what became a more and more theoretical right to vote. ${ }^{18}$ In an interview shortly after the Birmingham monument came down, Woodfin described these monuments as celebrations of systematic racism based on claims of the biological inferiority of Black people. ${ }^{19} \mathrm{He}$ explained that his role as mayor was to fight the disparities in education, unemployment, incarceration, and even life expectancies created by centuries of disparate official treatment of Birmingham's white and Black residents. Woodfin also thought that the racist intent of the officials who put up the city's monument at the turn of the century was ridiculously clear. The base was inscribed with a text dedicating it to the Confederate dead, but Birmingham was founded in 1871, well after the war. By 2020, in a majority-Black city, the monument was an unwanted celebration of a past Birmingham did not even possess.

And so, Woodfin certainly did not regard the monument as "devoid of shape or meaning." His seemingly flippant 2019 statement was instead the product of legal limitations on what he could do about his beliefs. His predecessor, William A. Bell, had pledged to remove the monument, only to be sued by a Confederate heritage group. ${ }^{20}$ The resulting delay gave the state legislature enough time to pass a new law prohibiting the removal or alteration of public monuments over 40 years old. ${ }^{21}$ Conceding that he could not remove the monument, Bell instead ordered it covered in a plywood box. ${ }^{22}$ Alabama's attorney general then sued the city, claiming this covering

18 Thompson Smashing Statues, 121-143.

19 Morris, Alex. An Interview from Birmingham City Hall: Mayor Randall Woodfin on Toppling Racist Monuments, in: Rolling Stone, July 9, 2020. https://www.rollingstone.com/politics/politics-features/birmingham-alabama-mayor-randall-woodfin-confederate-statues-racism-1026205/.

20 Save Our South v. Mitchell et al., 01-CV-2015-903224.00 (Circuit Court of Jefferson County, Alabama, 2015).

21 Ala. Code §41-9-232. Cason, Mike. Gov. Kay Ivey Signs Bill Protecting Confederate Monuments, in: AL.com, May 25, 2017. https://www.al.com/news/birmingham/2017/05/gov_kay_ ivey_signs_bill_protec.html.

22 Edgemon, Erin. Birmingham Covers Confederate Monument as City Considers Removal, in: 
illegally altered the monument and demanding a fee of $\$ 25,000$ for each day the box remained in place. ${ }^{23}$

The city's appeal of this order was still pending when Woodfin came to office. He felt so strongly about the injustice of the state forcing Birmingham not only to keep, but to look at, a monument the majority of its citizens found abhorrent that he considered removing it despite the law, but feared he might be removed from office and criminally prosecuted. ${ }^{24}$ When, in 2019, he claimed he would give the monument to "any Confederate museum that wants this thing," he likely thought that persuading a Confederate heritage group to lobby the state legislature for an exception to the law would be the only route to rid the city of it. But in January 2020, the state's highest court held that Birmingham was liable only for a single $\$ 25,000$ fine..$^{25}$ Five months later, surrounded by protestors at risk of serious injury from makeshift attempts to topple the monument, Woodfin decided that paying another $\$ 25,000$ fine for again violating the law, by removing the monument, would be well worth it.

Like Alabama, the Southern America states with the most Confederate monuments generally have strict laws preventing local authorities from removing or altering them. ${ }^{26}$ In these states, towns are often more diverse and liberal than conservative, majority-white state legislatures, meaning that many communities, like Birmingham, have resented Confederate monuments for generations with no legal recourse for removal.

Another key difference between the historical iconoclasts Freedberg discusses and those operating today lies in the nature of their encounters with images. Freedberg's iconoclasts chose to enter the museums or churches where they encountered art, and they did not have a sustained prior relationship to their target. The man who slashed The Night Watch with a pocketknife in 1911 did so upon seeing it for the first time. Freedberg convincingly describes such iconoclasts as fighting against their own to idiosyncratic, overwhelming response to the artwork. By contrast, most recent protesters

\footnotetext{
AL.com, August 15, 2017. https://www.al.com/news/birmingham/2017/08/defy_state_law_ and_remove_conf.html.

23 Alabama v. City of Birmingham, Jefferson Circuit Court (CV-2017-903426).

24 Thompson Smashing Statues, 123-124.

25 State v. City of Birmingham, 299 So. 3d 220, (Ala. 2019).

26 Phelps, Jess R. and Jessica Owley. Etched in Stone: Historic Preservation Law and Confederate Monuments, in: Florida Law Review 71 (2019).
} 
have had long-standing relationships with public monuments, which they understand as strategic attempts to oppress the members of a minority group to which they belong. And their encounters are not voluntary; the monuments are forced on them when they visit a courthouse, post office, university, or other inescapable, prominent location.

A group of protesters hitching a monument to a truck under the cover of darkness seem to be compelled by unthinking iconoclastic impulse only if you don't see how these violent, illegal topplings are the results precisely of the laws that remove any peaceful, legal routes to achieving a community's wishes. And ignoring the role of law and politics in recent iconoclasm is fatal to Freedberg's method. He often protests critics who claim he ignores context. Freedberg does not deny that the particular time and place of an action, as well as the idiosyncratic personal history of an actor, are indeed important. But he is simply more interested in examining essential, biological responses to images. Since he cannot access these deep responses directly, he instead analyzes responses by separating out their parts: those dictated by circumstances and those attributable to a neurological response. But to achieve this separation, he needs to understand which parts of the response are attributable to which cause. Instead of acting out of a neurotic, attention-seeking impulse and an over-sensitive inability to tolerate images, those who took down monuments in 2020 seem to have made deliberate decisions that rationally respond to monuments, considering legal and political constraints.

I have been interviewing such protestors while writing a book about controversies over American monuments, and have found that they state a wide variety of motivations for their actions. These complexities are generally ignored in the news coverage Freedberg seems to have relied upon to get his picture of recent events. It should please Freedberg that the one thing these protestors have in common is a deep awareness of the way monuments function as images to encourage certain responses. Many protestors understand that the monuments they seek to remove were created to take advantage of what Freedberg identifies as "our inclination to lapse into empathy before all images." Like Saint Bernard's Virgin, these monuments render abstract ideologies comprehensible and attractive by representing them in desirable human form. What better way to convince viewers of the superiority of the "Anglo Saxons" than by showing them attractive representatives of the race? Putting up a few signs to offer more facts about the oppressiveness of these ideologies will do little to stop viewers from reacting sexually to the beautiful images. But decreasing the attractiveness 
of an ideology by decreasing the physical attractiveness of the bodies used to represent it makes a great deal of sense. Toppling a monument will not disprove the ideology that created it. But it will take away one of its most potent means of spreading.

To write Power of Images, Freedberg paid exacting attention to often-overlooked historical sources of information about responses to images. He built up his theories about our relationship to images from this comprehensive and nonjudgmental review. Iconoclasm stumbles both when he failed to collect enough information, as in the case of the Birmingham monument, and, more seriously, when he allows his existing theory to color his interpretation of new information. This is most evident in the book's chapter about a 2012 painting titled The Spear, a portrait of Jacob Zuma, then president of South Africa, painted with a large penis hanging from his open trousers. ${ }^{27}$ There is no question that the painting was critical satire of Zuma, who had been tried for rape in 2006, but even critics firmly convinced of his guilt decried the way the artist relied on a racist trope about the supposed sexual prowess of Black men.

Freedberg was expelled from South Africa, his home country, as a young man because of his political activity in the early 1960s. In this essay, Freedberg writes movingly about the crucial role that posters and other visual art played in the resistance to apartheid, and activists' stratagems for outwitting the government's tight censorship of any potentially subversive expressions. Convinced that censorship is a mechanism of oppressive state power, Freedberg is dismayed that The Spear was vandalized by activists and was removed from view. When Freedberg wrote about the controversy previously, a South African publisher refused to publish images of the painting. But Freedberg reproduces The Spear in his book, seemingly because he does not believe that the painting was actually harmful. For him, those who criticized it for perpetrating stereotypes were using a pretext to rally support for Zuma in an upcoming election. "Every powerful image arouses deep emotions," he concedes - but he argues that viewers gave The Spear the heightened attention that any explicitly sexual image receives, and that this response was manipulated into a politically expedient reaction. ${ }^{28}$

27 Freedberg, Iconoclasm, 182-201.

28 Freedberg, Iconoclasm, 195. 
Although, Freedberg closely examined what protestors said about their reaction to the image, he disbelieved them because their reports did not match his theory about sexualized response being a more basic component of our relationship with images than responses based on, for example, group identity or personal trauma.

Despite its lacunae, Iconoclasm still contains valuable insights into current controversies about monuments, whether Freedberg makes these points himself or allows readers to draw out comparisons on their own. "When fear of the power of images is broken in the heat of iconoclasm," he writes in a chapter on the Beeldenstorm, "it takes some time and effort before that feeling seeps back into the imagination." ${ }^{29}$ Catholic services were restored in the Netherlands, with new paintings and sculptures made to replace the broken ones, soon after the concentrated attacks on images of 1566 . Just as in 2020, authorities rushed to clean up signs of disturbance. But in 1581, the Netherlands saw a quieter but "a great deal more systematic" outbreak of iconoclasm. One suspects that the fast-acting intensity of protests in late 2020 will have similar aftershocks, now that we have demonstrated to ourselves that public monuments are not so immovable as they attempt to seem.

\section{References}

FREEDBERG, David. The Power of Images: Studies in the History and Theory of Response. Chicago: University of Chicago Press, 1989.

. Iconoclasm. Chicago: University of Chicago Press, 2021.

HUANG, Mengfei, Holly Bridge, Martin J. Kemp, and Andrew J. Parker. Human Cortical Activity Evoked by the Assignment of Authenticity when Viewing Works of Art, in: Frontiers in Human Neuroscience, vol. 5, 134 (2011).

PHELPS, Jess R. and Jessica Owley. Etched in Stone: Historic Preservation Law and Confederate Monuments, in: Florida Law Review 71 (2019). 
THOMPSON, Erin L. Smashing Statues: The Rise and Fall of American Monuments. New York: Norton, 2022.

TWAIN, Mark. A Tramp Abroad. Hartford, Conn: American Publishing Co, 1880. 